\title{
Symposium on the Futures of the Islamic World
}

\author{
Algiers, Algeria \\ 8-11 Shawwāl 1410 / 4-7 May 1990
}

\section{Mahdi El-Mandjrah}

I am honored to be among such a distinguished group of people who have contributed so much to identifying the problems besetting the Islamic world. The subject under discussion highly strategic, especially at this time of sweeping upheaval and distuption that has been anticipated for years by future studies specialists. I thus have no illusions about the awesome task we face and am fully aware of the subject's complexity.

I have been working in the field of future studies for over twenty-five years and have participated in approximately two hundred international conferences and seminars related to this subject. This is the first time, I think, that an international symposium has been entirely devoted to the identification and analysis of current and anticipated problems as related to Islam. This is a sign of the maturity of the Islamic world, and similar initiatives must be encouraged in the future with the hope of initiating and supporting concrete research projects in this important area.

Given the countries of origin of this symposium's participants, I hope that its sponsors will consider extending its activities beyond the scope of the Arab world. After all, Arabs are only 20 percent of the total Muslim population. When dealing with Islam, we must all beware of ethnocentric temptations, for Islam calls for a diversity that is conducive to unity. This prescription is enshrined in the Qur'an:

O mankind! Lo! We have created you male and female, and have made you nations and tribes that ye may know one another. Lo! the noblest of you, in the sight of Allah, is the best in conduct. (49:13)

Accordingly, I consider this symposium to be a sort of rehearsal for other meetings to come and which will be more representative of the realities and potentialities of the Islamic world. We should therefore avoid the confusing generalization which has led the West to apply the specific reality of the Arab region to all countries of the Islamic world. This is not to be regarded as a critical stand against this symposium, but rather as an expression of a personal reservation concerning possible attempts to con-

Mahdi El-Mandjra is a futurologist and a professor in the College of Liberal Arts, Muhammad V University, Rabat, Morocco. 
fer universal validity on the proceedings and findings of this meeting. This presentation covers three major areas: the importance of future studies, contemporary realities, and prospects for the Islamic world.

\section{The Importance of Future Studies}

As we are addressing the future prospects of Islam, allow me to clarify some Islamic concepts. In Islam, a clear distinction must be made between the Arabic word al ghayb (the unknown), which is within the realm of God, and the word al mustaqbal (the future), which implies the anticipation of developments arising from what we do or fail to do today. We are not talking about prophecies but about forecasts. In fact, the word al mustaqbal does not occur in the Qur'an. Instead, we find a derivative: al mustaqbil, as in:

Then, when they beheld it as a dense cloud coming toward their valleys, they said: Here is a cloud bringing us rain. Nay, but it is that which ye did seek to hasten, a rain wherein is painful torment. (46:24).

The Qur'an abounds with references to the notions of perception, outlook, and the future:

Oh ye who believe! Observe your duty to Allah. And let every soul look to that which it sent on before for the morrow. (59:18)

Have they not considered the dominion of the heavens and the earth, and what things Allah has created, and that it may be that their own term drew nigh? In what fact after this will they believe?. (7:185).

Have they not seen how We have appointed the night that they may rest therein, and the day sight-giving? Lo! therein verily are portents for a people who believe. And (remind them of) the Day when the Trumpet will be blown, and all who are in the heavens and the earth, will start in fear, save him whom Allah wills. And all come unto Him, humbled. And you will see the hills you deemed solid flying with the flight of clouds: the doing of Allah who perfected all things. Lo! He is informed of what ye do. (27:86-8)

These verses tell us to make the best possible use of the present and to prepare carefully and intelligently for the rest of our life on earth and the hereafter. Here are other Qur'anic verses that make the same point: 
And let every soul look to that which it sent on before for the morrow. (59:18)

Send him with us tomorrow that he may enjoy himself and play. And Lo! we shall take good care of him. (12:12)

And say not of anything: Lo! I shall do that tomorrow. (18:23)

No soul knows what it will earn tomorrow, and no soul knows in what land it will die. (31:34)

Tomorrow they will know who is the rash liar. (54:26)

It should be noted that whereas the first of these verses calls for exploring the future so as to strengthen the believer's faith in God, the third and fourth verses dismiss any form of prophecy or divination.

In analyzing the above verses, we see that the Qur'an advises against making presumptuous claims of prescience and foreknowledge. However, it recommends that we make projections and work out different options in order to enhance our ability to cope with the requirements of the future and to improve our well-being. Therefore the future should be approached in a pluralistic manner ("futures"), leaving open a wide range of options.

Islam is a "vision" of life on earth and also in the hereafter. It calls on the individual human being to seek command of his/her own fate and to adopt, for this purpose, a dynamic approach as regards his/her political, economic, social, and cultural initiatives. Indeed, change is an essential ingredient for a better future: "Lo! Allah changeth not the condition of a folk until they [first] change that which is in their hearts" (13:11).

One must therefore avoid confusing the concept of bid ' $a h$ and $i b d \bar{a}$ '. The first is an opinion or attitude that violates the basic tenets of Islam. The second is, on the contrary, an invitation to introduce changes and innovations in order to stimulate the community's development and vitality. Any living organism which does not accept change is doomed to extinction. This applies to human beings as well as to their environment.

Those who are opposed to change are afraid to lose their privileges. This is why they tend to equate change with heresy. This conservative attitude was a determining factor in the decline of the Islamic world and in the proliferation of its problems. Attempts to check the imagination and stifle innovative efforts began in the tenth and the eleventh centuries, when so-called religious scholars "closed the door" of ijtihad.

How are we going to make up for lost time? By searching for an answer, one may realize the importance of the study of the future and the necessity of scouting and scrutinizing the "horizons": 
We shall show them Our portents on the horizons and within themselves until it will be manifest unto them that it is the Truth. Doth not thy Lord suffice, since He is witness over all things?. (41:53)

The Prophet always looked forward to the future and very rarely looked back to the past. It is even said that he always looked ahead when he walked. Islam is a faith and a way of life, an exploratory vision of life on earth and in the hereafter. Our outlook determines our deeds, for which we are held accountable, to ourselves, to society, and to God. In Islam, an individual is ever mindful of the impact of his/her action on the rest of his/her life as well as on his/her fate on the Day of Judgment.

The Prophet was reported as saying that Islam erases past sins, meaning that a new Muslim should no longer worry about past actions but instead think about the future. It also means that he/she will be held responsible and answerable for his/her present and future deeds. The Qur'an says in this connection: "And yet every soul look to that which it sent on before for the morrow" (59:18).

These preliminary remarks are meant to ward off any misconception about Islam being fatalistic to the extent that individuals and society as a whole have no control over themselves. But as Shaykh Mohamed Belarbi Alaoui put it forty years ago, we must get rid of all of the garbage that we have accumulated in our own brains before attempting to confront the challenges of the future.

The study of the future is a fairly recent exercise, for it began only at the end of the Second World War. The first future surveys were carried out, in 1946, by the Rand Corporation for the Pentagon. This accounts for the fairly close relationship between strategic studies and future studies. It was in the late 1960s that future studies began to be a distinct activity. At present, two-thirds of all future-related research work is carried out by military institutions and multinational corporations. Scientific research activities are funded along the same lines.

Future studies are thriving in the industrialized nations, which account for 97 percent of all future studies expenditures, particularly in the fields of training, documentation, and scientific research and its applications. With 80 percent of the world population, the Third World accounts for less than 3 percent of future studies output. In fact, underestimating the strategic value of the future is one of the most significant symptoms of underdevelopment. I find it difficult to explain a seemingly paradoxical rule whereby the more acute and pressing a phenomenon is, the more we need a long-term approach to deal with it efficiently. Development actually begins when people have secured the means to ponder their future and reach a consensus on the type of society they wish to build.

Future studies are not a science in themselves, although they make use of exact and social sciences. What they consist of is the studying, 
from an open perspective and on the basis of alternatives and options, of various developments in regards to a given situation and of the possible consequences on those developments of implementing a certain decision. This is why we talk about futures as opposed to one future. The basic purpose of this exercise is to set desirable objectives and to see how they can be achieved in the medium or long term by acting upon the present.

When Einstein was asked why he was interested in the future, he simply said: "I intend to spend the rest of my life there." One of the major functions of future studies is of a pedagogical and educational nature, as it changes mental attitudes and contributes to reducing the time needed to keep abreast with and make use of rapidly expanding knowledge.

I have always emphasized that cultural values are essential ingredients of development. Islam is a powerful factor of change and innovation and, as such, is bound to play a vital role in the evolution of our society. This development is all the more likely as more and more people, especially the young, develop a thirst for spiritual values to compensate for the excessive materialism of contemporary society. When young Muslims return to their cultural sources, it is because they are seeking guidance from their endogenous values. The future that the Arab-Islamic world is looking for depends on the revival of Islam in its innovative acceptance, not on the Islam of blind imitation that led to the fall of a once-brilliant civilization. If the Prophet and his Companions had failed to imagine and visualize the future, there would probably not be as many as 1.2 billion Muslims in the world today.

\section{Contemporary Realities}

The world today has many distinct features, the most prominent being:

An acceleration of history. The total amount of knowledge accumulated in the world doubles every seven or eight years. Every two minutes, there is a new scientific article published somewhere in the world. This has led to two further developments: increasing complexity and a shrinking of time and space.

A move from a production-based society to a knowledge-based society. Human resources are now becoming more important than raw materials (whose price is in constant decline), and capital is no longer sufficiently profitable unless accompanied by "added values" (intellectual input and innovation). To get an idea of the speed with which history is moving and of the scope of the changes brought about as well as their implications, especially with respect to human resources, one can read a survey conducted by the Spanish Ministry of Higher Education. There it is stated, among other conclusions, that training provided by post-secondary 
educational institutions does not prepare people for half of the jobs that will be in the labor market by the year 2000 .

The role of culture is on the increase. During the first North-South panel sponsored by the Society for International Development (SID) in Rome (May 1978), I argued that the most determining aspect in North-South relations was the cultural aspect, as this concerns the values that determine the attitudes of individuals and societies. I told the audience that:

We must address the question of value systems as a matter of priority in order to show that the current crisis between the North and the South cannot be overcome merely through adjustment efforts. In fact, the crisis affects the system as a whole. Any solution therefore requires that the objectives, functions, and structures be reconsidered. It also calls for redistribution of power and resources according to values and criteria which must be different from those which brought about the collapse of the current system.

Population. The population of the South is young and growing fast, while that of the North has been stabilized and is aging. Fifty percent of the Muslim population is under 16 , while more than 60 percent is under 30 .

Advanced technology. This area (i.e., computer science, cybernetics, robotics, artificial intelligence, space technology, and biotechnology) are thriving in an industrial sector that devotes 8 to 12 percent of its turnover to research and development and almost as much to staff training. The socalled "transfer of technology" is a hoax consisting of palming off obsolete products on the South at unjustifiably prohibitive prices. Control of technology requires internally expended efforts and endogenous research. Technology is not a commodity that can be purchased or sold; rather, it is a long process based on knowledge and creativity.

Information and communications. These are expanding activities and now account for over 40 percent of the world's industrial output and 60 percent of the labor force. The gap between North and South is incredibly wide - the North controls over 85 percent of all information-related activities. We have hardly begun to understand the political and economic, social, and cultural impact of this sector.

The economy. There is a need for economic integration and the establishment of economically viable entities. No economic community with less than 150 million inhabitants can make it successfully into the next century (Europe [EEC]: 350 million; North America: 350 million; Southeast Asia: 350 million). 
Culture. Culture is the most strategically important element in relations between nations. More than political and economic problems, those related to cultural communication are likely to cause conflict in the future.

Modernity equals westernization. This concept has turned out to be unfounded. This is proven by the Japanese experience. The Nippon Institute for Research Advancement (NIRA) published a report entitled "Agenda for Japan in the 90s." Here is an excerpt which I quote quite often:

It has become necessary to look at the world system differently, to put aside a long-sustained view of world order based on stratification under American rule. The new world order may be called the "Age of Diverse Civilizations," based on the emergence of an age with multiple co-existing civilizations. Although westernization led to progress on a worldwide basis in terms of material civilization, Japan's modernization served as evidence that modernization is different from westernization.

Scientific Developments. There is a tendency for the "immaterialization of matter" and the "materialization of the immaterial." Fewer and fewer raw materials go into industrial products. Conversely, "gray matter" input generates more and more added value. An example of "immaterialization" is the increasing utilization of optical fiber, which has led to a sharp decrease in the use of copper in miniaturized devices, microprocessors, and electronic chips. The economy is said to be getting more immaterial.

In addition, "new" scientific branches like particle physics, molecular biology, and neurophysiology have developed and expanded to such an extent that they are now challenging conventional Newtonian physics on the grounds that it is basically mechanical physics and that it fails to explain all of the phenomena that are observable in the universe. Similarly, Descartes' rationalism is being criticized as an obstacle to the understanding of phenomena not falling within the rigid scope of Descartes' "method." The consequence is that there is no longer a clear-cut demarcation line between material and immaterial realms.

How can one claim to be a Muslim when one is not in a position to comply with the first injunction from Allah? Indeed, the first Qur'anic verse calls on Muslims to ". . read in the name of thy Lord ... .," and yet the majority of Muslims have no direct access to the Qur'an except through intermediaries.

One of the great merits of Islam is its abolition of the idea of a clergy, thus making it possible for the believer to communicate directly with God. Is the scourge of illiteracy still plaguing us just because we cannot afford the necessary means to eradicate it? Is it because there is no political will to fight it? Or maybe because some rulers are afraid that 
an educated Muslim society might bring about dramatic changes in the way the Muslim community is being ruled and managed?

The fact is that we have failed to develop our human resources, the most valuable asset for any society, and will continue to fail to do so in the future. Worse still is the fact that we are affording the luxury of holding back the emancipation of half of the Muslim population: the 500 million or more women subjected to anti-Islamic policies in complete disregard for the Qur'anic prescriptions concerning the rights of women. This is one of the most serious and pressing problems that must be dealt with promptly and efficiently in the Muslim world.

The major feature of the Islamic world today is underdevelopment. Some of its aspects are as follows:

Economic and sociocultural data on the Islamic world are unavailable. The best data banks and research programs on Islam are found in the industrialized nations. What is striking is that quite a few of these activities are funded by "donations" from our own countries. Another disturbing fact is that we are so poorly informed about our own affairs that it was the Vatican who published, in the early 1980s, the first estimates of the size of the Muslim population. This study was the result of a ten-year survey for which six hundred people in not less than two hundred countries and territories had been mobilized.

Our recent history is still colonized. Our present, for the most part, is beyond our control. Even our future is now mortgaged, because we tend to rely blindly and unreservedly on scenarios and surveys drawn up and doled out to us by others. The chances are that our future might become a distorted and useless image of the others' past. The stark reality is that the Muslim world has no control over its destiny and that it enjoys only nominal independence in many areas. In short, decolonization is still a remote target that will take decades to reach.

Another distressing evidence of our resignation over our future was provided 108 years ago by the British orientalist W. C. Blunt, author of The Future of Islam. It was not until 1985, more than a century later, that a Muslim by the name of Ziauddin Sardar issued a similar book-The Future of Muslim Civilization-in London.

Lack of a clear vision. One of the greatest handicaps of the contemporary Islamic world is that the ruling elite has no clear vision of the future and its requirements. It is unaware of the currents of thought shaping today's reality and insensitive to the major preoccupations of the population. On the other hand, it is afraid that any move or initiative by a segment of society might impair or restrict its privileges, authority, and influence. 
Other failings. Other shortcomings and drawbacks include a tendency for blind imitation of the West, for docile compliance with "recommendations" coming from foreign intelligence sources, and with "directives" issued by advisers sent to us by protecting powers both from the East and the West. There is also no willingness to consult the population, seek its views, or accommodate its aspirations. The citizenry is kept away from the decision-making process. They also have no say in the formulation of programs and policies that might be instrumental in dealing with growing challenges and in achieving possible and desirable objectives, as well as developing a civil society with the necessary legal safeguards.

Our rulers' attention is focused on the slightest move by their opposition, for they are convinced that their opponents want to topple them and remove them from power. Given this view, when it comes to tackling the ills of society they can only improvise patchwork solutions and soothing measures with no lasting effect. In fact, they deliberately avoid any long-term planning and concentrate their efforts on time-winning devices. They fool themselves with the illusion that they are vigilant enough to foresee and to deal successfully with the oncoming changes.

Illiteracy. The Islamic countries lead the world in this category. In some countries the figures are as high as 80 percent, while they are over 50 percent in many others. The situation is becoming increasingly serious, as there are no effective literacy programs underway. Worse still is the fact that a new type of illiteracy is emerging among those who are literate: they are being subjected to brainwashing and turned into ignorant people totally unaware of what is going on in their country and their surroundings. There is no hope for the Islamic world to improve its condition in the future unless it resolves to wage an effective war against illiteracy by implementing a five-year program and mobilizing all of its energies and goodwill to eradicate this scourge. But for the time being, the sad reality is that the number of students in schools remains very low, and the number of educational institutions, training centers, libraries, hospitals, and publishing houses is far from adequate.

The quasi-absence of scientific research. This activity requires a sound academic environment and a solid educational base, as well as genuine freedom of expression, all of which foster creativity and innovation. Unfortunately scientific research in the Islamic world, and in the Third World at large, is attracting only nominal interest and hardly any investment. As a result, the brain-drain phenomenon continues to grow as more and more scientists leave for other countries either in search of better job opportunities or because their initial environment was not propitious for career development and self-accomplishment. 
In this connection, I would like to make it clear that there can be no development of scientific research, and therefore no progress, without the full restoration of the tradition of ijtihad. Ijtihad must be understood and accepted as a modern exercise designed to preserve the fundamental tenets of Islam and discard all obstacles hindering the emancipation of the Muslim community and keeping it in a state of decadence and backwardness. In addition to ijtihad, political pluralism and civil liberties must be established and given free rein.

The worsening crisis in social and cultural values. Most of our leaders have only a shaky and dwindling credibility. There is considerable improvization, carelessness, and nepotism in the way they run their countries' economies. Bribery is almost standard practice. Their massive, and hardly secret, bank transfers abroad are not only an insurance policy against adversity but also an efficient tool to manipulate internal policies from the outside. Hence a collapse of moral and ethical values.

Exogenous development models. Our development planning is based on blind imitation of the West and heavy dependence on western assistance. It is sad to note that policymakers in the Islamic world make no allowance for science and technology in their development schemes. They seem to forget that development is not merely a program for distributing revenue and providing services. As Rene Mahue, former director general of UNESCO, said: "Development is when science becomes culture."

Insufficient respect for the rule of law and lack of safeguards for the protection of civil liberties and human rights. Too many Islamic countries live under political systems in which power is monopolized and freedom of opinion and speech are restricted. Where repression, denial of basic rights, and violation of human dignity are the daily lot of the citizenry, there is no hope of creating an environment that favors the development of human resources and knowledge and the advancement of society as a whole. The right to speak, to express one's differences, to innovate, to create, and to publish one's findings will remain an illusion so long as we have not ensured respect for human rights and the rule of law.

The status of women. The condition of our women is alarming. Their essential role in development is not fully recognized. By hampering their advancement we are preventing the emancipation of half of our society. It is a crime to keep more than half a billion of our fellow citizens in such a precarious condition. If Muslim society is essentially backward, it is mainly because we have confined our women to a marginal role.

As we are addressing the issue of Islam and its prospects, we must make it clear that it is a shame that some practices, lies, and other ves- 
tiges motivated by the thirst and struggle for power from a bygone time are still prevalent in our society. I am not a specialist in Islamic law, so I consulted qualified experts on the status of women in Islam. They maintain quite clearly that a number of impostors had forged prophetic hadiths or written new ones and then attributed them to the Prophet. These forged texts, they explained, were then taken up by some pseudo-religious scholars and their followers who have spread them among the people until our own day. In so doing, they are distorting the true image of Islam and hindering their society's progress and development.

One such allegation consists of telling men that they can consult women but should never act upon their advice. In the opinion of hadith specialists, to attribute such an allegation to the Prophet is a sheer lie. Another so-called hadith, fabricated and spread by tyrants and imposters to suit their own purposes and hold back the Muslim community, claims that when the Prophet was asked by his daughter about the most suitable thing a woman could do, he allegedly answered that "she should see no man and arrange for no man to see her." This is a fictitious and totally fabricated hadith that has nothing to do with the Prophet, especially since it blatantly contradicts various Qur'anic prescriptions.

When we consult reference books on hadith and read the writings of specialized commentators, we realize that a large number of women were legal experts in Islamic law, custodians and transmitters of hadith, or soldiers fighting side by side with men to uphold the banner of Islam. To give one example: Karīmah bint Ahmad of Marw knew al Bukhārī's Șahih by heart. She was praised and recognized for her outstanding achievement by Hāfiz al 'Asqalānī in his Fath al Bārī.

I do not wish to dwell too long on this subject, but I hope that the distinguished scholars who are with us today will enlighten the audience about the Prophet's sayings and deeds calling for women to be respected, honored, and treated on an equal footing with men in the spiritual field as well as in earthly matters and dealings.

Another instance of the marginal status of women is the fact that there are hardly any women attending this symposium. I kept telling the sponsors that it was necessary to provide for equal representation of women in this meeting, for we are discussing the future of the entire Muslim community. I reminded them that during his farewell pilgrimage, the Prophet called on his community "to treat women well." Are we treating our women well by keeping them chained in ignorance and confined to a marginal status with hardly any role to play in public life?

I emphasize that there is no future for Islam without the effective involvement of women in the community's affairs. There is no prospect for any Muslim society that continues to deny women the rights granted to them by Islam. This matter demands urgent attention and consideration from those who care about the future of the Islamic community and who 
wish to stimulate our potentialities and creativeness so that we may grasp and cope with the current problems and the challenges ahead.

The condition of women internationally, but particularly in the developing countries, reflects the strong relationship between the economic and sociocultural aspects of development on one hand, and the protection of public liberties and human rights on the other. Within the Islamic world, Arab countries are worse off than others in the fields of education and scientific research.

The condition of Muslim women, particularly in Arab countries, is a real challenge. It calls for serious social surveys and analyses and requires a great deal of self-criticism as well as the rehabilitation and mobilization of our "ijtihad resources." We must take a fresh look at the original sources of our culture and read again, carefully and in the light of modern developments, the teachings of the Qur'an to gain a deeper understanding of the nature and scope of our problems. This will help us to develop a clear vision of the short- and medium-term solutions needed to cope with the demands and challenges arising from the rapid movement of history.

I strongly believe that the status of women is one of the most pressing and challenging issues facing us today. We must stand up to the challenge at once and look for appropriate solutions by relying on ourselves, by using our own resources, by mobilizing all forces of goodwill, and by refraining from imposing on women any conditions other than those required of men.

Muslim minorities. There are many Muslim minorities currently fighting for survival within larger domineering groups. Some have found themselves isolated following the sudden interruption of a merger-process with other segments of larger communities. Others have stayed behind and clung to their land after the ebbing of Islamic civilizations in which they used to thrive. Another category of Muslim minorities consists of those who emigrated, for whatever reason, to foreign lands. Examples of such minorities include Muslim workers who emigrated to Western Europe, Muslim populations in the Central Asian Republics of the former USSR, and millions of other Muslims in India, China, and the Philippines. If we really care about the development and prosperity of the Islamic world, we must think seriously about the present condition and the future prospects of these minorities and seek to provide them with the necessary help to preserve their identity and cultural heritage.

The Palestinian issue. This question is of strategic importance for the whole Islamic world. To liberate the Palestinians from the sufferings they are enduring under an alien occupation is more than just a moral obligation for all of us. We have no alternative but to pool our resources and unite our forces to stand up to this challenge. I do not believe that we can 
achieve this objective merely through diplomatic niceties of the Camp David variety. Let us not forget the daily acts of terrorism and repression perpetrated against the Palestinians throughout the so-called "occupied territories," including Jerusalem.

Israel is afraid of the future. She will have no rest until each one of her neighbors has been neutralized and reduced to impotence. With unconditional support from the West, particularly the United States, Israel has managed to build up nuclear capabilities and to control space technology. In the meantime, we have remained virtually idle, particularly in these two particular fields, although we know that 45 percent of the world's uranium belongs to Islamic countries.

\section{Prospects}

The main feature of the contemporary international order is the increasing North-South imbalance, with the former controlling 80 percent of the planet's resources while having only 20 percent of its population. Such a blatant injustice cannot go on indefinitely. The North simply cannot afford to carry on with the same pattern of industrial development while ignoring the deteriorating situation in the South. It will have to reduce its consumption of energy by approximately 20 percent in the next ten to fifteen years. The North's overuse of the biosphere-a vital environment-has reached intolerable limits and is causing serious concern about the very survival of humanity. Although the UN General Assembly adopted a resolution in support of development policies during a special session on development, we know from the last thirty years of experience that such policies are inefficient and counterproductive.

I had meant in this presentation to address the question of what I call international hypocrisy, a practice in which governmental agencies from both the North and the South are the real culprits. I was also going to address the question of South-South cooperation by pointing out the fact that it is virtually at a standstill and that the South's dependence on the North is stronger than ever before. It was also my intention to speak of the role of Muslims in prospective studies.

I decided to confine this presentation to some of the most serious challenges facing the Islamic community. I made this choice because there are now approximately one billion Muslims. By the year 2020, there will be between 1.635 and 1.85 billion, or-approximately 25 percent of the world's population. These figures call for two important remarks:

The Muslim population continues to grow. This is of serious concern to the West and the Vatican, which has been closely monitoring demographic trends in the Islamic world since Muslims outnumbered Catholics for the first time in 1985. The following figures may explain why there is so 
much vigilance and concern: a) the size of the Muslim population will soon equal or surpass the entire population of the world as of 1830 ; b) in thirty years, the number of Muslims will equal the entire population of the world at the beginning of this century; and c) according to western sources, in 1980 Judaeo-Christians represented 31 percent of the world population as against 18 percent for Muslims. By 2025 the trend is expected to be reversed, with 25 percent for Judaeo-Christians and 33 percent for Muslims. Projections for the end of the twenty-first century put the ratio at 20 percent and 40 percent respectively. If this trend continues, within four or five generations Muslims will account for 50 percent of the world's population.

The western population is aging. As a result, within the next ten years it will be necessary to bring in more immigrants, preferably young and highly qualified, who will help the West maintain its comfortable living standard. But the West is even more worried by the increasing number of young Muslims. However, this younger generation is our best asset. We must cater to these young Muslims' needs and provide them with adequate education and training.

Internal disarray. The major factor here is the ruling elites' lack of vision and a common project for society. These people ignore or neutralize those with the qualifications, ability, and willingness to redress the situation. Some of the educated have become culturally alienated in their own countries. Others, out of self-imposed censorship, are silent and indifferent. The rest have just given themselves up to the highest bidder.

Internal spiritual and ethical crisis. This is reflected in our disarray in the face of contradictory value systems. One is static and unable to adjust to the new developments and challenges, and the other is alien and inconsistent with the needs of the new environment. This dichotomy perhaps explains why our youth are at a loss and are so suspicious of their elders.

Cultural vacuum. There is a wide vacuum in our society, and alien currents of thought are trying to sneak in and fill it up. One example of this is the "francophonia sect" that is being preached in the Maghreb region. Its zealous advocates are intent on erasing our language and culture and replacing them with an exogenous language (French) spoken by hardly 4 percent of the world's population.

Under the circumstances, we have no alternative but to mobilize our resources and do all we can to redress the situation and pave the way for a more secure future. All Muslims, be they in the East or in the West, must endeavor to fill the existing cultural vacuum, for it is said that nature does not tolerate a vacuum. 